This item was submitted to Loughborough's Research Repository by the author.

Items in Figshare are protected by copyright, with all rights reserved, unless otherwise indicated.

\title{
An exploration of the distractions inherent to social media use among athletes
}

\section{PLEASE CITE THE PUBLISHED VERSION}

https://doi.org/10.1016/j.smr.2019.12.006

\section{PUBLISHER}

Elsevier BV

VERSION

AM (Accepted Manuscript)

\section{PUBLISHER STATEMENT}

This paper was accepted for publication in the journal Sport Management Review and the definitive published version is available at https://doi.org/10.1016/j.smr.2019.12.006.

\section{LICENCE}

CC BY-NC-ND 4.0

\section{REPOSITORY RECORD}

Hayes, Michelle, Kevin Filo, Andrea Geurin, and Caroline Riot. 2020. "An Exploration of the Distractions Inherent to Social Media Use Among Athletes”. Loughborough University.

https://hdl.handle.net/2134/11897895.v1. 


\section{An exploration of the distractions inherent to social media use among athletes}

\section{Abstract}

4 Social media present athletes with a number of benefits and challenges. As a result, various

5 sport stakeholders have debated appropriate social media use among athletes at major sport

6 events, with some suggesting that using these platforms can have negative consequences. The

7 purpose of this research was to examine the elements of social media that athletes perceive to

8 be distracting during major sport events and the practices they undertake to address such

9 distractions. Interviews with Australian elite athletes $(N=15)$ were conducted and data were

10 analysed using thematic analysis. The findings reveal several elements associated with

11 distraction, including positive and unwanted messages, branding pressures, and competitor

12 content. Athletes reported two key practices that assisted in overcoming distractions,

13 including switching off and handing over the control of their social media accounts. The

14 findings extend distraction-conflict theory to athlete social media research, while presenting a

15 preliminary conceptual model to assist researchers in further understanding the potential

16 impact of social media distractions on athletes. Opportunities for sport practitioners to

17 develop or implement social media education programs are described.

19 performance. 


\section{$1 \quad 1$ Introduction}

Recent research suggests social media use may result in lower performance levels among athletes (David et al., 2018; Encel, Mesagno, \& Brown, 2017). The impact social media have on athletic performance has been debated amongst sport managers across a number of media outlets. Having an online presence increases fan accessibility to athletes, and in some cases can create an avenue for unwanted commentary. For example, the

7 Australian Olympic Committee (AOC) has acknowledged that the messages athletes receive can be a potential distractor and that negative public feedback, including online bullying, can elicit undesirable emotions in athletes (Australian Olympic Committee, 2015).

While negative messages sent by fans to athletes via social media could present a source of distraction, some athletes indicate that positive reinforcement posted to social media channels can also disrupt performance. Notably, following the 2012 Olympic Games, one high profile athlete blamed Twitter for her lack of a gold medal. Australian swimmer Emily Seebohm was one of Australia's most publicised medal contenders; however, she conceded social media may have been partly to blame for her not winning the gold medal after an influx of encouraging comments led her to believe she had won her final before the race began (Ottesen, 2012).

Reviews of research on sport and social media underscore a focus on the reasons athletes use social media among existing research (Abeza, O’Reilly, Séguin, \& Nzindukiyimana, 2015; Filo, Lock, \& Karg, 2015). However, empirical examination of the

21 link between social media use, distractions, and lower performance levels is limited. Both Abeza et al. (2015) and Filo et al. (2015) revealed research has heavily relied on content analyses methods (i.e., examining social media posts), revealing opportunities to utilise different data collection approaches, including interviews. As a result, opportunities exist to examine how athletes perceive social media as a potential distraction during high 
1 performance settings such as major sport events through the lens of distraction-conflict theory

2 (DCT). DCT allows researchers to examine how distractions and interruptions can affect

3 performance of a primary task (Baron, 1986). Within the current research, we conceptualized

4 the primary task for athletes as competing at a major sport event as these events present

5 athletes with greater stress levels. These events are of higher importance than regular season

6 matches with increases in performance expectations (Karageorghis \& Terry, 2011).

7 Therefore, many sport stakeholders (e.g., fans, media, and governing bodies) are quick to

8 judge athletes for their performances, especially if they do not meet expectations.

Through semi-structured interviews, we examined the elements of social media that athletes perceive to be distracting during major sport events. Further, the practices athletes undertake to address distractions was also examined through the lens of distraction-conflict theory. The current research contributes to DCT through a proposed conceptual model based on the three key steps of the framework. Specifically, we identify the entities that can present distractions to athletes through social media, the attentional conflict that can lead to impaired performance, and the practices used to address these distractions.

\section{Literature review}

\subsection{Distraction-conflict theory}

DCT provides a theoretical lens for researchers to understand the effect that distractions and interruptions have on the performance of a primary task (Baron, 1986; Brooks, 2015). DCT posits that the presence of others can distract an individual and could lead to attentional conflict (Sanders, Baron, \& Moore, 1978). The theory can be broken down into three steps: (a) other people are distracting, (b) distractions can lead to attentional conflict in individuals, and (c) the attentional conflict leads to elevated drive (Baron, 1986; Brooks, 2015), which in turn can increase the occurrence of impaired performance (Baron, 1986; Brooks, 2015). The purpose of the current research is to examine the elements of social 
1 media that athletes perceive to be distracting during major sport events and the practices they

2 undertake to address such distractions. DCT accepts that attentional conflict can be created

3 from both internal and external distractions in pressure settings (Baron, 1986) and can occur

4 when a person feels obliged or the tendency to allocate their attention to more than one

5 stimulus (Baron, 1986; Sanders et al., 1978). The theory also assumes that distractions will

6 not always cause attentional conflict. Instead, it represents the conflict an individual has in

7 determining how to allocate attention (Baron, 1986), providing an appropriate lens to

8 understand the experiences of athletes in competition settings and whether social media

9 presents issues in terms of attention allocation.

10 Existing literature has identified that athletes utilise social media for a variety of

11 reasons (e.g., Browning \& Sanderson, 2012; Geurin-Eagleman, 2016; Hayes, Filo, Riot, \&

12 Geurin, 2019). In contrast to this well-established area of literature, less is known about the

13 impact the platforms may have on an athlete's performance through distractions during major

14 sport events. DCT has been used to examine the impacts of social media and productivity in

15 other user groups (Brooks, 2015). The theory provides an appropriate lens to examine the

16 elements of social media perceived to be distracting through its three-step model. For

17 instance, the first two steps suggest that others are distracting and that these can lead to

18 attentional conflicts. As social media facilitates connections between different users, athletes

19 may experience distractions from any notifications or messages they receive from followers

20 (Encel et al., 2017). The third step of DCT suggests that the attentional conflict created by

21 others can lead to impaired performance. Yet, athletes who can maintain their focus on

22 achieving peak performance during events are typically more successful (Greenleaf, Gould,

$23 \&$ Dieffenbach, 2001). Therefore, DCT provides an opportunity for researchers to examine

24 the potential impacts concentration disruptions solicited through the elements of social media 25 may have on athletes. 
The theory has been previously used to examine how the presence of others can be a distraction and the effect these distractions have on the performance of a primary task (Sanders et al., 1978). Sanders et al. (1978) described a distraction as any stimuli that are irrelevant to the primary task, while a primary task was defined as the activity in which a person gives their full attention. In the context of the current research, the primary task for an athlete is competing at a major sport event, while a distraction during this task could include reading social media messages or accessing social media platforms. DCT has been utilised in a variety of studies, mostly within the social psychology discipline. However, limited research applying this theory has been undertaken in the area of sport and social media.

Although DCT has rarely been applied in the sport and social media discipline, the theory has been effective in examining the impacts new technologies, such as social media, have on an individual's performance of a task. Brooks (2015) suggested that frequent use of social media leads to lower performance levels on the task at hand and that social media have the potential to be a distractor among individuals. DCT can be applied to the current research as the theory provides a framework for researchers to examine the effects that a distraction caused by social media can have on performing tasks (Brooks, 2015). Other researchers have examined instant messaging interruptions in the workplace and the influence on task performance (Gupta, Li, \& Sharda, 2013). These studies demonstrate that social media can lead to distraction and a decrease in productivity or task performance.

However, minimal attention has been directed at the elements of social media that could impact athletes during major sport events. Sport practitioners may also benefit from such an investigation, as social media support and management programs could be tailored to the specific areas where athletes experience distractions. These support programs may include adapting training and education resources, which have been utilised to ensure athletes use social media appropriately (Sanderson, Browning, \& Schmittel, 2015) and could 
1 minimise any negative impacts on athlete performance.

\subsection{Social media impacts on athletes}

Traditional media has been a cause of distraction and stress among elite athletes competing at the highest level. Early research by Greenleaf et al. (2001) examined the factors that influence performance during the Olympic Games and revealed that an increase in media attention produced by traditional media sources created a distraction for athletes. Similarly, other studies identified media to be a key stressor for athletes (e.g., Durand-Bush, \& Salmela, 2002; Kristiansen, Hanstad, \& Roberts, 2011; Noblet \& Gifford, 2002). Media stress was derived from athletes feeling pressured to engage in media activities to create publicity for their sport. There was no mention of social media in these studies, which may have been due to the timing of the research (i.e., before the widespread introduction of social media). However, athletes may experience these stressors in a social media context, whereby they are pressured to maintain their brand (Geurin, 2017; Parmentier \& Fischer, 2012).

Smith, Arnold, and Thelwell (2018) revealed that social media could heighten traditional media stressors in athletes. In an examination of cricket captain biographies, one athlete highlighted that social media can intensify the scrutiny and criticism received from traditional media and followers as the platforms are accessible 24 hours a day, 7 days a week. Further, social media allows athletes to receive negative comments instantaneously before, during, and after competitions. However, whether these comments could have impacted athletic performance was not determined, revealing an opportunity to further examine the elements of social media athletes perceive to be distracting.

Social media platforms have provided fans and followers with an avenue to express their opinions of athletes, both positive and negative. As a result, online abuse of athletes has become a significant problem (Kavanagh, Jones, \& Sheppard-Marks, 2016). Disgruntled fans can bully or blame athletes in online settings, including via social media, if their performance 
1 does not meet expectations (David et al., 2018; Farrington, Hall, Kilvington, Price, \& Saeed,

2 2014). Social media may also provide an avenue for fans to direct sexist remarks, physical

3 threats, and emotional ridicule towards athletes (Geurin, 2017; Litchfield, Kavanagh,

4 Osborne, \& Jones, 2016, 2018).

5

6

Sanderson and Truax (2014) highlighted an increasing development whereby fans attacked college athletes via social media after athletic competitions with messages manifested through belittling, sarcasm, threats, and mocking. Receiving these types of messages from followers may provide athletes with an attentional conflict during their event. Some athletes have highlighted that they spent too much time reflecting on critical messages during training, resulting in extra work to improve on aspects of their performance that were criticised (David et al., 2018). Athletes may also feel compelled to respond to the negative commentary (Browning \& Sanderson, 2012). Yet, how athletes perceive these messages in terms of distraction, and how this is managed during a major sport event requires further exploration.

Beyond the presence of cyber bullying, researchers have focused their attention on the link between social media use and mental health problems. Although not specific to athletes, a large amount of literature has focused on investigating whether social media is responsible for increased mental health problems among adolescents (Berryman, Ferguson, \& Negy, 2018; Jensen, George, Russel, \& Odgers, 2019; Twenge, Joiner, Rogers, \& Martin, 2017). These findings may have applications to athletes competing in major sport events as many athletes are within the adolescent age group. Twenge et al. (2017) reported that adolescents who spend large amounts of time on social media were more likely to report mental health problems when compared to those who spend most of their time engaging in other activities (e.g., in-person interaction). Several studies have uncovered findings in contrast to this work suggesting that the frequency of social media use may be a poor predictor of mental health 
1 problems among adolescent groups. Instead, problems associated with social media may be

2 due to how people are using the platforms and what content they are engaging in (Berryman

3 et al., 2018; Jensen et al., 2019). Athletes may experience issues when reading or receiving

4 content about themselves that is negative (Sanderson \& Truax, 2014). Therefore, it is

5 important to examine the elements of social media that athletes perceive to be distracting or

6 impactful.

7

The dominance of social media has also been suggested to have negative influences on well-being through decreases in self-esteem and self-image in young people (Richards, Caldwell, \& Go, 2015). Further, Błachnio, Przepiorka, and Pantic (2016) highlighted that those addicted to social media or are intensive users can experience lower life satisfaction. The negative influences of social media on well-being and self-esteem may be due to users engaging in social comparison (Vogel, Rose, Roberts, \& Eckles, 2014). These findings may be applicable to athletes in the current research. For instance, Hayes et al. (2019) suggested that some athletes are affected by seeing their competitors on social media and experienced feelings of anxiousness as they compared their content to others.

Although there are several negative aspects associated with social media use, the platforms may also provide some benefits to athletes. For instance, Internet applications and social media can be used as a diversion from competing pressures (Frisby \& Wanta, 2018; Hayes et al., 2019). This may be particularly important for athletes who experience feelings of stress during major sport events. Researchers have also paid considerable attention to how and why athletes use social media. These studies have identified several positive impacts that have benefited athletes including the ability to manage their personal brands, market themselves to potential sponsors and gain endorsements, and increase their interactions with fans (Browning \& Sanderson, 2012; Geurin-Eagleman \& Burch, 2016). Social media also provide athletes with an avenue to stay connected with their support networks during major 
1 sport events (Hayes et al., 2019). Maintaining connections with support networks allows

2 athletes to feel a sense of positive reinforcement. However, whether athletes desire

3 distractions during major sport events and how these are pursued through social media

4 requires further exploration. As a result, the first research question is advanced:

5

6

Research Question 1: What elements of social media do athletes perceive to be distracting during a major sport event?

Meanwhile, athletes have described several strategies to deal with negative comments received via social media (Browning \& Sanderson, 2012). Some athletes chose to ignore messages, delete the person sending the messages from their feed, or in some instances, respond to messages. Responding to the messages could cause more issues or aggravate the situation, but athletes indicated that they found the messages difficult to ignore. Athletes who attempted to delete or block those individuals directing negative comments have sometimes been unsuccessful, as new accounts can be easily created. Although these strategies were reported by student-athletes dealing with negative commentary during a season of competition, other practices that might be utilised to address additional distractions associated with social media remain unclear, revealing an avenue for further exploration.

There is a small body of literature that has specifically investigated the effects social media have had on athlete performances through sport anxiety. Athletes of varying levels have experienced concentration disruptions through their Facebook use prior to a competition (Encel et al., 2017). Enabling specific features unique to social media, such as push notifications, escalated the risk of athletes experiencing an increase in disruptions. In the same study, $68.1 \%$ of the sample accessed Facebook two hours prior to a competition, while $31.9 \%$ used the platform during a competition. Enabling notifications could increase the chance of an athlete viewing any negative messages that have been sent or posted to them from followers and other social media users, potentially causing an attentional conflict when 
1 preparing to compete at a major sport event. Therefore, it is plausible for some athletes to

2 acknowledge notifications and messages as a distraction and undertake measures to minimise

3 the impact on their performance. To explore these practices further, a second research

4 question is posed:

Research Question 2: What practices do athletes utilise to address social media distractions during a major sport event?

\section{Method}

To address the research questions advanced, an interpretive constructivist philosophical approach was undertaken. This approach allowed the researchers to develop an understanding of an individual's reality and how it is created by delving deep into their consciousness (Sparks, 1992). Specifically, an interpretive philosophical approach allowed the researchers to create an understanding of the elements of social media that athletes perceive to be distracting. Research positioned within the interpretivist paradigm requires the use of qualitative methods to explore participant experiences such as interviews, focus group discussions or ethnographies (Antwi \& Hamza, 2015; Creswell, 2014). As athletes were located in different geographical areas due to training and competition commitments focus group discussions would have presented practical constraints. A qualitative research design was chosen for several reasons. First, Auerback and Silverstein (2003) described qualitative research as the first step in building knowledge relating to phenomena. Second, a qualitative research design facilitated the ability to obtain more in-depth data (Tracy, 2013) from the athletes about experiences with social media distractions. Semi-structured interviews allowed more in-depth information in relation to the participant's viewpoints and experiences to be collected (Horton, Macve, \& Struyven, 2004).

\subsection{Participants}

The sample consisted of elite athletes $(N=15)$ who agreed to partake in a semi- 
1 structured interview. All participants had represented Australia at a major sport event (e.g.,

2 Olympic Games, Commonwealth Games, or World Championships). Female $(n=9)$ and

3 male $(n=6)$ athletes were interviewed and ranged in age from 18 to 34 . The number of years

4 representing Australia on a national team at major sport events also varied between athletes

5 from one year to over 10 years. Access to athletes presented a pragmatic constraint to the

6 current research (Suri, 2011). These athletes were chosen based on their experience on the

7 national team and the availability of their contact information via social media platforms. The

815 athletes maintained a presence on one or more social media platform (e.g., Instagram

9 and/or Facebook). Some participants disclosed that they created a separate Facebook page for

10 their athlete profile which was used to showcase their sporting life and maintain privacy in

11 their personal lives. Instagram was the most popular platform among the sample and showcased both sport and personal content. The number of followers on Instagram ranged between approximately 430 followers and 19,400 followers. The follower numbers may have been influenced by the career stage of each athlete as some had competed on the Australian national team for only one year prior to interviews. Further, the publicity and profile of each of the sports may have influenced the number of followers for each athlete. For example, soccer and basketball have been included in the Olympic and Commonwealth Games but also have separate professional and semi-professional leagues in Australia.

Australian athletes were chosen for several reasons. First, like other countries,

Australia has been described as a sporting nation with a long tradition of focusing on international sport achievements (Stewart, Nicholson, Smith, \& Westerbeek, 2005), while a significant amount of government investment is designed to achieve international success (Hogan \& Norton, 2000). Australia's focus on international sport success provides an avenue to explore whether social media is perceived to impact athletic performance during major sport events. The money invested in achieving international success comes with increased 
1 criticism from media, with some labelling the platforms as a distraction from competition and

2 a potential contributor to disappointing results in international competitions (e.g., Fynes-

3 Clinton, 2012). Second, examining Australian athletes responds to a call for more social

4 media research to incorporate perspectives outside of North America (Filo et al., 2015). Table

51 provides an overview of participant demographics. Confidentiality was ensured using

6 pseudonyms.

7
--TABLE 1--

\subsection{Materials}

Prior to conducting interviews, an interview guide was developed containing a list of open-ended questions. Using open-ended questions was consistent with the philosophical approach and qualitative methodology (Antwi \& Hamza, 2015). These questions allowed athletes to answer freely, while the semi-structured approach ensured that relevant information about social media distractions was being obtained (Horton, Macve, \& Struyven, 2004). First, demographic information was obtained from participants including age, gender, sport, and years on the national team. As few studies have examined athlete perceptions of social media distractions, several questions were more general and open to allow for gathering a basic understanding of how athletes felt about social media as a distraction during the preparation phase of an event and during actual competition. For example, one of the first questions posed to athletes was, "Do you think using social media is distracting during major sport events?" Athletes were asked to elaborate on their answer through questions such as, "Why do you think this?" The remaining interview questions were based on the three steps of DCT theory and gaps in the literature.

The first step of DCT posits that others can be distracting (Sanders et al., 1978). Following this step, athletes were asked questions about the people they interact with on social media and the messages from followers they received at events (Geurin, 2017; 
1 Sanderson \& Truax, 2014) and whether they believed these messages could cause attentional

2 conflicts. Expanding on the work of Browning and Sanderson (2012), athletes were also

3 asked how they responded to messages or performance pressures. As DCT focuses on

4 attentional conflicts caused by distractions through step two (Baron, 1986) several questions

5 were incorporated into the interview guide to discuss whether athletes have experienced

6 issues relating to the allocation of their attention. Specifically, participants were asked to

7 provide an example of whether they experienced an attentional conflict, and whether they

8 perceived this to negatively impact their performance. A broad question was created to reflect

9 the second step of DCT, "Was there a time when or where your attention was focused on

10 social media rather than the event you were competing in?" Follow up questions occurred

11 based on each athlete's answer to the question, such as, "Could you explain this example in 12 detail".

13 In order to explore whether the elements of distraction identified through the

14 previous questions could impact performance (step three of DCT), one question consisted of,

15 "How could a reliance or time spent on social media affect athletic performance levels?" A

16 copy of the interview guide can be found in Appendix A. The semi-structured interview

17 approach allowed for some flexibility during interviews whereby the researcher could further

18 pursue certain comments made by participants (Horton et al., 2004).

\subsection{Procedures}

Following ethical approval from the researchers' institution, athletes were recruited

21 through a purposeful and convenience sampling approach consistent with qualitative

22 methodologies (Etikan, Musa, \& Alkassim, 2016; Lincoln \& Guba, 1985). Athletes were

23 selected via a purposeful approach in order to develop an understanding of the research

24 problem and answer the research question(s) (Creswell, 2014). The convenience sampling

25 approach was facilitated by the geographic location of the authors (Etikan et al., 2016), as 
1 access to athletes presented a pragmatic constraint to the current research (Suri, 2011).

2 Athletes were identified through publicly available team list announcements for major sport

3 events and recruited through personal email addresses provided on their websites and social

4 media pages. The recruitment email consisted of an introduction, an overview of the research,

5 and request for participation. A gift card prize draw incentive was used to encourage athletes

6 to participate. This consisted of a first prize valued at $\$ 100$ and second prize worth $\$ 50$. Interviews were conducted between February and June 2018. The interviews lasted between 20 and 45 minutes and were conducted via telephone $(n=10)$, Skype $(n=4)$, and

9 face-to-face $(n=1)$ based on the preference and location of participants. Interviews were 10 conducted until data saturation occurred. After conducting 15 interviews, it was determined 11 that the saturation point had been reached, as no new content or themes became apparent 12 (Gratton \& Jones, 2004). Researchers have suggested that data saturation in qualitative studies typically occurs within the first 12 interviews as 97\% of important codes are obtained

14 during this time (Guest, Bunce, \& Johnson, 2006). After 13 interviews, similarity across

15 themes became apparent and new information was no longer being obtained. An additional

16 two interviews that had previously been scheduled were conducted to ensure that the

17 saturation point had been reached. At the completion of these two interviews, it was confirmed that data saturation had been reached. Previous research examining the distractions faced by athletes and the psychological impacts of social media have collected data from

20 similarly sized samples (e.g., David et al., 2018; Greenleaf et al., 2001). Interviews were

21 audio recorded on a digital recording device. Recordings were uploaded to an electronic folder and sent to a professional service to be transcribed. Once completed, member checking was carried out whereby participants were sent a copy of their transcription and asked to comment on the accuracy (Creswell \& Miller, 2000; Smith \& McGannon, 2018).

\subsection{Data analysis}


An interpretive constructivist approach requires researchers to search for patterns, themes and holistic features within the data (Antwi \& Hamza, 2015). Therefore, interview transcripts were analysed by the first author using thematic analysis. Thematic analysis allows sport researchers to examine people's behaviours and their views on a specific issue or phenomena (Braun, Clarke, \& Weate, 2016). Thus, thematic analysis is an effective method in sport research. Thematic analysis can be used across a variety of methods but has been most commonly applied to qualitative studies involving interview data. The process included: (a) familiarisation with the data, (b) generating initial codes, (c) searching for themes, (d) reviewing themes, (e) defining and naming themes, and (f) producing the report (Braun \& Clarke, 2006). Thematic analysis is commonly used in qualitative interviewing as the technique allows researchers to examine the chosen sample's behaviours and views on a specific issue or phenomena. Data were analysed manually through the use of Microsoft Word documents and a Microsoft Excel spreadsheet. The lead researcher read through each transcript multiple times in order to become familiar with the data. While familiarising herself with the data, the researcher applied DCT theory as a guiding framework to identify interesting features of the data and assist in generating initial codes related to the research questions.

Once data and corresponding initial codes were entered into the spreadsheet, the sorting function was used to group codes together. Once the initial codes and potential themes were identified, they were sorted with corresponding data extracts (i.e., quotes from athletes). Once the themes were finalised, they were defined before a review for any overlap was conducted. While engaging in the thematic analysis phases and applying DCT theory as a framework, seven themes were identified including obligation to respond, susceptibility to unwanted commentary, pressures of maintaining and building a brand, competitor content, mood management, need for self-awareness, and switching off and handing over control. 
As data were coded by the first author, the researcher approached the thematic analysis process reflexively to minimise bias and subjectivity (Morrow, 2005). Reflexivity was carried out through peer debriefing consultations with the remaining research team members, who are experienced in qualitative methods, to minimise bias. Peer debriefing sessions included extensive discussions about the themes that were derived from the analysis in order to elicit alternative interpretations (Lincoln \& Guba, 1985; Morrow, 2005).

Throughout the peer debriefing process, several questions were asked by the remaining research team members about the themes and what they contained. A number of changes were made to themes from peer debriefing discussions including minor amendments to three theme names and redefining two definitions for clarity. Member checking was carried out to enhance the rigour of the current research (Smith \& McGannon, 2018). Participants were given an opportunity to assess the trustworthiness of the research in two phases. As previously outlined, athletes were sent a copy of their transcript. Next, participants were sent a summary of the researcher's initial interpretation and asked to comment on whether it was accurate and/or a realistic representation of their experiences (Creswell \& Miller, 2000). The research team did not receive any requests for alterations to the summary. The themes along with an operational definition and example quote are outlined in Table 2 and are presented in the following section.

\section{--TABLE 2--}

\section{Results}

\subsection{Distracting elements of social media}

Five themes were revealed in relation to the first research question regarding the elements of social media that athletes perceive to be distracting during an event: obligation to respond, susceptibility to unwanted commentary, pressures to build and maintain a brand, competitor content, and mood management. The themes reveal that the distracting elements 
1 of social media are not necessarily all negative.

\section{$2 \quad$ 4.1.1 Obligation to respond}

This theme was defined as athletes receiving an influx of messages and feeling compelled to reply. Athletes reported receiving primarily positive messages, but on occasion received negative comments or messages. The theme appeared to affect athletes on both personal and professional levels as some experienced feelings of guilt when they could not respond to all messages. Further, it appeared that athletes appreciated the positive comments and messages but the influx of messages received during a major sport event, compared to the number they were used to receiving, was difficult to manage for some athletes. The positive messages made athletes feel supported, however some highlighted that it was difficult to respond to all messages. Matilda explained her experience:

It is hard, especially when people private message you, as opposed to just posting a comment. I think, if they post a comment, they don't necessarily us their support. or supportive messages sent to her via social media:

It's just like sometimes you don't have the time to reply back, and you're like, oh maybe I should, maybe I shouldn't sort of thing. I definitely haven't replied to all my messages since I got them, I just don't have time to read through all of them and do all these individual messages back, lots of stuff. But it is nice. Like, it is encouraging. Vanessa emphasised the importance of trying to stay focused on the event before 
1 responding to messages by saying, "Once I had nothing on, like, me and my friend, we were

2 on the bus and we were like, oh we probably should reply to some messages now."

\subsubsection{Susceptibility to unwanted commentary}

In contrast to responding to supportive messages, some athletes also revealed they would receive unwanted commentary. The theme was defined as social media providing an avenue for followers to direct antagonistic messages to athletes. Athletes explained that unwanted commentary was not hard to find if they searched for them. However, they also highlighted that it was important not to go searching for this content in order to avoid developing undesirable feelings. The finding was suggested to impact athletes more on a personal level, however, if not managed appropriately the commentary could begin to affect them professionally. The theme was relevant for both event and non-event times, however athletes suggested they were more susceptible to unwanted commentary due to the extra attention afforded to them during events. Warren highlighted that seeing negative comments while already stressed can lead him to have further doubts about his own abilities and performances by saying:

Normally it doesn't bother me, and I'm quite entertained by people trying to troll me, because I find it pretty funny, but it's not stuff that you want to read when you're extra stressed. Just to put a doubt in your mind.... Some people get really upset by it.

Although she rarely received negative comments, Gwen highlighted that the unpleasant messages from followers can add to stress and foster undesirable emotions. She explained by saying:

If I'm already feeling down on myself for some other reason and that comment came in, I may not as easily be able to put it aside. Also, if for example I saw it just before I went out and competed versus the night before, like if it was the 
night before, then I would have time to kind of process it and change it into whatever I want to change it into whereas if I saw it a half an hour before I was about to climb, like that would be different.

\subsubsection{Pressure to build and maintain an athlete brand}

The third element revealed athletes felt pressure to build and maintain a brand.

The theme was defined as the perception that creating a brand through social media is time consuming and can distract athletes from focusing on the event. Branding pressures appeared to impact athletes both personally and professionally. As many of the athletes were not receiving full salaries, obtaining sponsorships would have enabled them to supplement their living allowances to continue their involvement in their sport. Major sport events presented an opportunity for athletes to capitalise on the additional media coverage provided to their sports. This extra media and viewer attention may have also provided an opportunity for sponsors to increase the exposure they receive, which may have resulted in athletes feeling pressured to post a certain amount of content to meet their contractual obligations. However, Oscar highlighted the importance for athletes to balance their branding expectations, but not let it take over during important moments within events:

Yeah, in terms of managing it [the brand] so that you are meeting requirements and stuff but it's not sort of taking over your life too much. Especially when it comes to competing because it can possibly ruin your race if you're worried about that sort of stuff too much.

In addition to time constraints, some athletes may become too invested in their brands rather than focusing on competing. Vanessa revealed she has seen athletes find it difficult to manage their brand when it came to competing instead of focusing on the competition: "when they compete, they're sort of like, torn between what I should do and what I should look like, 
1 and stuff, and between actually just competing and let their results sort of show."

\section{$2 \quad$ 4.1.4 Competitor content}

The fourth element of social media reported to be distracting was competitor content.

4 The theme was defined as athletes seeing their competitors' posts on social media and

5 question their own preparation leading up to the event. Several athletes illustrated that they

6 were friends with their competitors and enjoyed seeing their content and interacting with

7 them on social media during non-event times. However, the competitor content appeared to

8 impact athletes on a professional level as some indicated that once they were competing at

9 their major sport their competitors' content could make them second guess their own

10 preparation or abilities. Yvonne highlighted that competitor content could be distracting,

11 suggesting it can make athletes think about their competitors rather than focus on themselves.

12 She said, "For example if you saw, um, a competitor posting something you could be distracted, um, thinking about what they're going to do rather than thinking about your race."

14 Gwen, who competes for Australia but currently trains in another country, detailed her experience seeing her competitors' content on social media: What I would say is most - I don't know if it's distracting, but most impactful to performance, is seeing other athletes' postings on social media. So, for example, one of my closest rivals trains in Brisbane and because I'm not living in Australia, I can't access the same services that she has through the [organisation] and so she posts videos and photographs of things of the work that she's doing with them and I'm looking at those and going - constantly second-guessing, 'Oh, am I doing the right things? Should I be doing that thing that she's doing? Oh, how do I look compared to her? Is she a bit stronger than me?' like all of that sort of stuff.

Meanwhile, Warren added that competitors' content may not affect all athletes and 
1 suggested that those with more experience understand that social media can be used as a way

2 to unsettle the competition:

You can appreciate what they're doing, but not worry about it. And that comes with practise and experience, and a bit of maturity, but for sure, for some of the younger people, it absolutely gets to them. And I know that, so that's why I put some stuff up. And that's just knowing how it works, and that they [competitors] obviously put up their best stuff to show it off and psych out the competitors.

\subsubsection{Mood management}

The final element reported by athletes was mood management. The theme was defined as athletes seeking a distraction or reprieve from the sport/competition through social media during an event. Athletes revealed that social media provided an escape from the pressures of the events and a way to manage their moods, indicating that not all social media distractions are negative during major sport events. The context of the current research may have influenced the finding due to the competitive environments sport events present to athletes. The theme highlighted how social media can affect athletes on a personal level, which can then be translated to their professional lives. Mood management appeared to be conducted through general scrolling of social media newsfeeds (i.e., athletes were not searching for specific information). Using social media as a diversion from competition pressures also did not typically include responding to comments by followers. Victoria revealed her feelings toward using social media for mood management by saying, "It gives me some time to switch off and not think about it [the competition] and get distracted. Sometimes distraction is actually a really good thing." Gabriella supported Victoria's sentiment by saying she has specifically used social media for a distraction during her event. She explained that using the platforms was a way to distract herself from the nerves associated with an upcoming match: 
I think there are times where I've used social media as a distraction. For example, if it was the day of the game and we didn't play until the night time, and it was an important match. I think in order to not think about the match and the nerves, I would use social media a lot to distract myself from that.

This finding indicates that not all distracting elements of social media are negative as the platforms can provide athletes with a desired diversion from competition pressures. In addition to the elements of social media athletes perceive to be distracting, the current research explored the practices athletes employ to address these distractions.

\subsection{Practices undertaken to address distractions}

Athletes reported a number of ways they addressed distractions. Two themes were evident: need for self-awareness and switching off and handing over control. Both themes are presented in the following sections. These practices were primarily implemented to address the negative distractions experienced with social media use.

\subsubsection{Need for self-awareness}

The first practice used to address social media distractions was having a need for selfawareness. The theme was defined as athletes being aware of how social media affects them, discovering what works for them to minimise any impacts, and prioritising activities. Athletes highlighted this practice across most areas of their social media use to address both personal and professional concerns. For example, if an athlete was beginning to feel affected from the amount of unwanted or negative content directed at them or second guessing their preparation and abilities, they would undertake other practices to minimise any negative outcomes. Gwen described her experience with social media distractions by indicating she can acknowledge when her use may be affecting her preparation or performance and then make the necessary changes:

In terms of the impact that it can have, yeah, it is definitely impactful and it 
requires a level of, um, self-awareness to know that that's happening, um, selfregulation to know how to deal with it and then self-discipline to, you know, when it is actually affecting my performance or my preparation, choosing not to engage in that way, maybe shutting off social media altogether or whatever. Sam indicated he did not have many issues with social media in terms of distraction, but suggested other athletes experiment and find what works for them:

But I think a lot of it is, you know, just experimenting, seeing what works for you, yeah. I found that—-because if you don't need to relax maybe it's better for you to drop the phone and try to be more focused. But if sometimes people are too testy, you know—maybe it's better to relax a bit, go on social media, and just go through it a bit. But, I guess that it is not for everyone.

Many athletes were also aware that they would need to prioritise certain activities

(e.g., recovery) before using social media to post photos or respond to messages. Chloe explained that athletes should know what their priorities are and when they can go on social media by saying, "You've got to, you know, set your priorities and go on it when you should be on it, and not on it when you shouldn't be on it."

\subsubsection{Switching off and handing over control}

The second practice was defined as athletes switching off from their social media for a specified period of time (e.g., during competition) or handing their accounts over to someone else to manage throughout an event. After engaging in self-awareness and identifying the elements of social media that were impacting them, athletes described they would either switch off or give control of their accounts to a trusted family member. Switching off was mostly used to combat issues related to messages, both positive and negative. For example, some athletes advised their followers that they would not be using social media during the event to maintain focus on their performance and thanked them for 
1 their support in advance. Natalie suggested that social media can impact each athlete

2 differently, but revealed she deleted some of her social media apps before the competition by

3 saying, "I guess it's how you use it, but I use a social media lockout for I think four days. As

4 soon as I started training, I deleted Facebook and then, when I was on Twitter, I'd just scroll

5 the feed." She also said that looking at social media after a disappointing performance would

6 bring her mood down by adding, "because it will probably just enforce what's happened and

7 bring your mood down a little, so I guess you want to just focus on changing things, not on

8 the past." Chloe revealed that turning off her notifications allowed her to miss seeing her

9 friends organising an event to watch her compete during the Olympics. She revealed that if

10 she saw the messages and knew her friends were watching she would have felt more nervous

11 and added pressure:

So, for my second race, I - as I said, I didn’t check my notifications. After I competed, I read through all my notifications, and there were a few from my friends, like a bunch of my friends got together to watch the race, and I didn't under pressure, because so many eyes on me. So glad I didn't see that beforehand, because I would have gotten way more nervous with that. Other athletes handed the control of their social media accounts to someone else they trusted (e.g., family members). Engaging in this practice still allowed athletes to have a social media presence during an event, while allowing them to avoid content that might be harmful to their performance (e.g., seeing competitor content). Athletes stressed the importance of handing control over to someone trusted and who knows them well in order to maintain authentic content. Lincoln realised that some of the things he saw on his social media platforms affected his moods and possibly impacted his performance. He made the choice to 
1 hand over his accounts to his sister:

I found personally for me, I found it quite beneficial; what I did, I deleted the apps off my phone and I had my sister running, um, my social media accounts during the events... what I do during events is, so if I shut down my all my apps I use WhatsApp is the way that I contact with the people that I want to contact. Overall, there were a number of elements associated with social media that can be distracting to athletes. By addressing social media distractions, athletes may be able to minimise the impacts on their performance during major sport events. The next section discusses these findings in relation to previous research and articulates the contribution to the literature and DCT.

\section{Discussion and conclusion}

The current research utilised semi-structured interviews with elite athletes to understand the elements of social media athletes perceive to be distracting during major sport events, and the practices they undertake to address these distractions. Two research questions were advanced. The first research question asked: what elements of social media do athletes perceive to be distracting during a major sport event? Five themes were revealed including obligation to respond, susceptibility to unwanted commentary, pressures to build and maintain a brand, competitor content, and mood management.

Athletes disclosed they felt obligated to respond to messages they received via social media. The finding aligns with those of Browning and Sanderson (2012), who suggested that some athletes may feel compelled to respond to messages. However, Browning and Sanderson's (2012) research was conducted in the context of negative messages. Instead, the current research suggests that athletes feel a sense of guilt for not responding to positive messages. This may be due to the appreciation athletes have for receiving messages of support from their followers and wanting to connect with them. Yet, the time constraints 
1 during events made responding to all messages difficult.

In addition to the positive messages, social media made athletes susceptible to

unwanted commentary which were reported to increase the likelihood of undesirable

emotions (David et al., 2018; Kavanagh et al., 2016; Sanderson \& Truax, 2014). These

comments may have made athletes feels as though their effort or achievements were not good enough or could have been elicited through performance pressures reported in traditional media. Yet, the responses to unwanted commentary varied among athletes. Some athletes responded to negative messages, while others disclosed that they mostly tried to ignore them (Browning \& Sanderson, 2012). The varied responses may have been due to content of messages and experience of each individual athlete. For instance, a more experienced athlete emphasised the importance of not allowing the comments to affect their mindset while competing and may have had previous experience dealing with these situations. Younger and less experienced athletes may have more difficulty overcoming these messages. some in terms of prioritising their image over their performance, while others suggested it was time consuming (Hodge \& Walker, 2015). Athletes may find branding time consuming due to the expectations of the brands they are targeting. Further, a vast amount of literature has demonstrated that social media are beneficial for athletes in terms of branding (e.g., Arai, Ko, \& Ross, 2014; Hambrick \& Mahoney, 2011). However, some athletes preferred to let their performance speak for itself (Arai et al., 2014). The performance of athletes is regularly reported by a variety of sources, which may present one reason some athletes prefer to focus on their performance to build their brands. The theme presents new information to research that has found traditional media as a stressor for athletes (e.g., Kristiansen et al., 2011; Noblet \& Gifford, 2002). For instance, some athletes have experienced pressure to engage in media activities to publicise their sport, while the current research suggested similar experiences 
1 occur in a social media context.

Competitor content was a cause for additional stress and anxiety. According to Dale (2000), athletes can be distracted by seeing their competitors during events. Yet, the current research reveals that social media facilitates additional access to an athlete's competitors.

5 Although this is the case, athletes also articulated that they can learn from their competitors

6 by viewing their social media posts. If athletes use social media to study their competitors,

7 they could elicit feelings of excitement in learning new skills (Fitriana \& Xin, 2019) and overcome the chances of being distracted by their social media content.

Athletes revealed that not all distractions associated with social media are negative.

The final theme related to research question one (i.e., mood management) suggests that athletes purposely seek a distraction through social media in order to switch off from the pressure a competition presents. Mood management has been noted as an important driver in the selection of certain media (e.g., Johnson \& Knobloch-Westerwick, 2014), which is supported by the current research as athletes appeared to be driven to use social media to experience a diversion from competition pressures. The current finding contributes to research that has identified the role social media and networking sites play in mood management (e.g., Heinonen, 2011; Johnson \& Knobloch-Westerwick, 2014) by illustrating that athlete exposure to social media during events assist in maintaining a more relaxed state by creating a diversion from competition pressures.

The finding extends Frisby and Wanta's (2018) work on Internet application to social media through the identification of mood management as a key driver in creating a diversion from the pressures of competition. Relaxation strategies are an important feature of athletes' psychological preparation for a competition or major sport event (Ungerleider, 2005).

24 Therefore, it may be beneficial for athletes to have access to social media during events if they experience these positive effects. The finding contributes to literature that has identified 
1 the benefits social media provide to athletes (e.g., Browning \& Sanderson, 2012; Geurin-

2 Eagleman \& Burch, 2016; Hayes et al., 2019). Specifically, the current research demonstrates

3 mood management as an additional motive for using social media.

The second research question asked: what practices do athletes utilise to address

5 social media distractions during a major sport event? Two themes were uncovered: need for self-awareness and switching off and handing over control. In terms of self-awareness, select interviewees highlighted that it was important to do what works for them in terms of their social media use. The finding adds to sport psychology literature which identified that changing routines that have worked in the past could interfere with an athlete's performance (Greenleaf et al., 2001). Therefore, it might be more harmful if athletes were to suddenly stop using social media during events if they are consistent users in everyday life or have found that using social media has relaxed them at previous events. Further, practicing selfawareness would enable athletes to elicit the positive impacts social media presents.

Finally, athletes revealed they would switch off from their social media or hand over control of their accounts to someone they trusted (e.g., family member). The finding could be explained by the coping strategies employed when dealing with traditional media stress. For instance, athletes use avoidance strategies in order to minimise media stress such as avoiding reading, seeing, or listening to anything mainstream media reports about them (Kristiansen et al., 2011). By switching off their social media accounts, athletes are able to avoid seeing any negative commentary directed to them. Some of the participants in the current research revealed they did not want to see anything negative that may alter their mood during the event, and as a result, switched off their accounts or handed over control to a family member. Connections with support networks have been associated with better performances in literature outside of the social media realm (Freeman, Rees, \& Hardy, 2009). Therefore, the finding highlights important implications for the role of athlete support networks as these 
1 people can assist in limiting social media distractions.

\section{$2 \quad 5.1$ Theoretical implications}

The findings of the current research contribute to theory and research efforts regarding athlete social media use in several ways. First, the findings are applied to the DCT three-step model through a proposed conceptual model. Second, an extension of the threestep model is also proposed including suggested practices to minimise the potential for impaired performance. Third, although several elements were reported to have a negative impact on athletes during events, social media acted as a tool for mood management. Finally, the current research identifies the combination of athlete social media use and the role of support networks as an area of research that should be explored further.

\subsubsection{Distraction-conflict theory}

Previous work has begun to examine the effects of social media distractions on different audiences such as employees through DCT (e.g., Brooks, 2015). Researchers have tested whether social media use can cause interruptions and impact work productivity and well-being (Brooks, 2015; Gupata et al., 2013). The current research extends DCT in two ways: (a) by applying the DCT three-step model to the context of social media and athlete performance at major sport events, and (b) by extending DCT beyond a three-step model with practices that could minimise impaired performance.

First, the findings of the current research contribute to the DCT model through the identification of the 'others' (step one) and the attentional conflict these 'others' may cause for athletes. Step one of DCT suggests others are distracting (Baron, 1986; Brooks, 2015). The current research identified a number of people (or 'others') associated with increasing the chances of a distraction to athletes during major sport events via social media. These people primarily included followers, competitors, and prospective sponsors. In terms of prospective sponsors, these people may inadvertently lead to distraction in athletes. 
Step two of DCT posits that distractions can lead to attentional conflict in individuals (Baron, 1986; Brooks, 2015). The current research identified the attentional conflicts athletes may experience as a result of social media use. Negative messages may have psychological impacts on athletes (e.g., David et al., 2018; Sanderson \& Truax, 2014; Smith et al., 2018), however, the current research indicated that although messages were mostly positive, athletes felt an obligation to respond and were conflicted due to time constraints while engaged in a competition. Unwanted commentary from followers was also suggested to cause extra stress in some athletes, potentially increasing the occurrence of attentional conflict. The current research lends support to previous research that identified an influx of messages can be considered as an interruption (e.g., Gupata et al., 2013). Further, athletes reported that seeing their competitors' content on social media sometimes made them rethink their own preparation, which was suggested to cause attentional conflict.

Athletes revealed they experienced additional pressures to build and maintain an athlete brand, which may be conducted to pursue sponsorships in order to generate an income or awareness of their sport (Parmentier \& Fischer, 2012). The current research highlighted it was challenging to find time to balance a brand while focusing on competing, while some athletes put more focus into their brands which may cause their performance to suffer. Notably, not all distractions associated with social media use produced an attentional conflict for athletes. Social media provided a desired escape that was speculated to have positive performance implications, rather than impair competition results. Finally, step three posits that the attentional conflicts created in step two will lead to an elevated drive, increasing the occurrence of impaired performance (Baron, 1986; Brooks, 2015).

The second contribution to DCT was through the identification of practices that address performance distractions related to social media. Athletes adopted two practices including a need for self-awareness and switching off along with handing over control of 
1 their social media accounts. These practices extend DCT beyond the three steps and suggest

2 that although athletes may experience attentional conflicts from using social media, there are

3 practices that can minimise the impact on performance. For instance, athletes acknowledge

4 that social media elements can impair their performance (step 3), but undertake certain

5 practices to address and minimise these distractions. Athletes have adopted a similar

6 approach to minimising social media distractions to those previously utilised for traditional

7 media (Kristiansen et al., 2011). The practices contribute to DCT by revealing that athletes

8 experiencing distractions can take approaches to minimise the level of impaired performance.

9 The application of the findings to the three step DCT model of the current research are

10 demonstrated in Figure 1.

\section{$12 \quad$ 5.1.2 Athletes and social media}

In addition to the proposed conceptual framework outlined above, the findings

14 demonstrate that athletes can utilise social media to manage their moods and escape the

15 pressures of a competition environment. Researchers have explored the connection between

16 social media and mood management (e.g., Heinonen, 2011; Johnson \& Knobloch-

17 Westerwick, 2014). However, few researchers have examined how using social media to manage moods during major sport events can impact athletes. Using social media for mood management may allow athletes to experience a more relaxed state in the lead up to their competitions and result in better performances. From an organisation and governance perspective, the finding may present challenges to sport organisations attempting to restrict when athletes can and cannot use social media.

The findings of the current research also highlight the important role support networks

24 play in assisting athletes manage their social media use during major sport events. To date, 
1 athlete support network research has examined their role as social facilitators in doping in

2 sport (e.g., Vakhitova \& Bell, 2018) and career transitions (e.g., Park \& Lavallee, 2015). The

3 findings of the current research suggest support networks can assist athletes in coping with

4 social media duties (e.g., branding) by taking control and posting content on their behalf.

5 Allowing support networks to control social media content may reduce the negative impacts

6 the platforms have on athlete performance (e.g., negative commentary and undesirable

7 emotions). Further, athletes highlighted that the authenticity of their content would not be

8 compromised as the person they choose to control their accounts is often a close family

9 member. Although beyond the scope of the current research, the nexus between social media

10 and athlete support networks opens an area of research that should be explored further by

11 researchers and practitioners.

\section{$12 \quad 5.2$ Managerial implications}

In addition to contributions to theory, the findings highlight opportunities for practice.

14 Previous research has established that social media training is desired among athletes and

15 sport organisations, as it is a more effective mechanism for minimising any issues related to

16 social media (Sanderson et al., 2015). Based on the findings of this research, organisations

17 can improve their training beyond the basics of what athletes should and should not post.

18 Practitioners may benefit from including strategies on how to filter competitors' posts so they

19 are not visible in the athlete's social media feeds, as this was a source of anxiety for some

20 athletes. This may simply include promoting the 'unfollow' or 'mute' functions provided on

21 most social media platforms for the duration of an event. Strategies on how athletes could effectively build their brand while minimising issues arising from distraction should also be included in the training. However, it may be easy for some athletes to avoid using these

24 strategies which highlight the importance of understanding any underlying psychological 25 factors. 
The findings present an opportunity for practitioners to assist athletes to further develop appropriate coping and mental skills to deal with any negative feelings related to, and beyond, social media use. As suggested by participants, these skills could be emphasised in personal development programs. Athletes have the ability to improve regulation of focus and emotional control with an enhanced understanding of these psychological skills (Dohme, Bloom, Piggott, \& Backhouse, 2019). Further, mindfulness training sessions may assist athletes in reducing the stress associated with social media use and potentially strengthen their performances (Goodman, Kashdan, Mallard, \& Schumann, 2014).

Next, social media may provide a tool for athletes to develop resilience. Resilience can be described as the internal and external qualities that strive for positive outcomes despite the presence of adversity (Galli \& Vealey, 2008). Athletes who use effective coping strategies (Thelwell, Weston, \& Greenless, 2007), and have appropriate social support (Rees \& Hardy, 2000) are more likely to be successful in relieving negative emotions associated with certain stressors. The current research revealed that social media facilitated the provision of positive messages to athletes, which could be viewed as a form of social support. Further, experiencing distractions provided an opportunity for athletes to undertake certain practices to minimise negative outcomes related to their performance. Coaches, instructors, or sport psychologists can help athletes develop resilience by promoting perceptions of selfconfidence and control when athletes are under pressure or experience adversity (Turner \& Barker, 2013), which may also be applied to issues related to social media use. Thus, an opportunity exists for practitioners to extend the concept of resilience to social media contexts.

Finally, this research revealed that social media provides an avenue for athletes to manage their moods and escape the pressure of competition. The finding presents an important implication for practitioners, as researchers have identified that pressure induces 
1 more distracting thoughts and worries which can lead to choking. Engaging in preventative

2 measures should aim to reduce worrying feelings (Oudejans, Kuijpers, Kooijman, \& Bakker,

3 2011). Social media presents one avenue that could assist in minimising these feelings if used

4 appropriately. For instance, coaches may allow athletes to use the platforms during times

5 when athletes begin to feel stressed or worried about their upcoming performance. However,

6 content that could present other issues (e.g., unwanted messages) should be disabled to

7 prevent undesirable emotions.

\subsection{Limitations}

Limitations of the current research are acknowledged. First, the current research consisted of a retrospective design. As a result, the potential for memory bias is present as participants were asked to recall their experience during their most recent event (Wimmer \& Dominick, 2003). We attempted to arrange interviews within a week of the athlete's most recent major event, however, not all were interviewed within this time frame. Therefore, recall may be affected due to the time lapse since the event occurred, as some athletes were interviewed up to two months later. However, the pragmatic constraints of accessing athletes amidst their busy schedules prohibited the research team from interviewing athletes closer to the events.

Second, limitations are inherent to the theoretical framework guiding the current research. DCT focuses on distractions associated with performing a certain task (Brooks, 2015). Therefore, other areas relating to athlete use of social media that could be problematic were overlooked. For instance, researchers have suggested that social media use may lead to mental health problems (e.g., Berryman et al., 2018; Jensen et al., 2019; Twenge et al., 2017). Whether these issues are present in athletes cannot be determined using DCT. Therefore, it is important for future research to utilise different approaches and frameworks to further develop the understanding of the impacts social media may have on athletes in both event and 
1 non-event contexts.

Third, due to the exploratory design of the current research and focus on athletes, the role of support networks was not discussed in depth. Athletes acknowledged that their family and friends would take control of their social media profiles during events to alleviate distractions. These support networks play an important role in providing athletes with emotional support which can lead to better performances (Freeman et al., 2009; Rees \& Hardy, 2000). Yet, few have explored the role of support networks in social media contexts.

Next, stakeholders such as sport administrators and coaches may influence athletes' use of social media during events or implement certain strategies to minimise distractions. For instance, previous research has identified that coaches encourage athletes to plan for distractions (Gould, Greenleaf, Guinan, \& Chung, 2002). Coaches may encourage athletes to switch off their platforms during events which could have influenced the current findings. Administrators utilise policies and education to assist with how social media is used (Sanderson et al., 2015) which could have influenced the current findings.

\subsection{Future research}

Several areas for future research have arisen and can address the limitations of the current research. First, researchers could consider conducting a longitudinal study to examine the impacts of social media on performance over a number of events. Longitudinal studies have also been recommended by researchers (e.g., Abeza et al., 2015) to help determine whether athletes develop sophisticated ways to use social media based on previous experiences. Longitudinal research could assist in identifying whether support or management mechanisms delivered by sport organisations effectively minimise social media distractions among athletes. Following longitudinal designs, athletes should be interviewed at two points in time at a minimum (Petersen, 1993). Interviews could be conducted after multiple events and/or post career. 
Second, researchers could utilise a qualitative research design including interviews or an open-ended questionnaire to further explore the role of support networks in alleviating

3 social media distractions to athletes during major sport events. Interviews with support

4 networks (e.g., family and friends of athletes) may flesh out how and why these groups take

5 control of athlete social media profiles and if there are any additional strategies they adopt

6 during events to minimise the impact social media distractions may have on performance.

7 This future research design would extend support network research to a social media context.

Finally, future research may also seek to gather the perceptions of other sport

9 stakeholders such as sport administrators and/or coaches. This proposed research could

10 investigate these stakeholder's perceptions of social media as a distraction and how this is

11 managed within their organisations and/or teams. To date, research has focused on how

12 organisations promote appropriate social media use in order to protect the image of sport

13 entities (e.g., Sanderson et al., 2015). A qualitative research design consisting of interviews

14 would be beneficial in gathering these perceptions and exploring the support or management

15 mechanisms adopted to minimise social media impacts on athletic performance. 


\section{References}

Abeza, G., O’Reilly, N., Séguin, B., \& Nzindukiyimana, O. (2015). Social media scholarship in sport management research: A critical review. Journal of Sport Management, 29(6), 601-618. https://doi.org/10.1123/JSM.2014-0296

Antwi, S. K., \& Hamza, K. (2015). Qualitative and quantitative research paradigms in business research: A philosophical reflection. European Journal of Business and Management, 7(3), 217-225.

Arai, A., Ko, Y. J., \& Ross, S. (2014). Branding athletes: Exploration and conceptualization of athlete brand image. Sport Management Review, 17(2), 97-106. https://doi.org /10.1016/j.smr.2013.04.003

Auerback, C.F., \& Silverstein, L.B. (2003). Qualitative data. New York, NY: NYU Press. Australian Olympic Committee. (2015, December 15). Athletes prepare for social media distraction. Australian Olympic Committee. Retrieved from https://goo.g1/qVa9oW

Baron, R. S. (1986). Distraction-conflict theory: Progress and problems. Advances in Experimental Social Psychology, 19, 1-40. https://doi.org/10.1016/S0065$\underline{2601(08) 60211-7}$

Berryman, C., Ferguson, C. J., \& Negy, C. (2018). Social media use and mental health among young adults. Psychiatric quarterly, 89(2), 307-314. https://doi.org/10.1007/s11126$\underline{017-9535-6}$

Błachnio, A., Przepiorka, A., \& Pantic, I. (2016). Association between Facebook addiction, self-esteem and life satisfaction: A cross-sectional study. Computers in Human Behavior, 55, 701-705. https://doi.org/10.1016/j.chb.2015.10.026

Braun, V., \& Clarke, V. (2006). Using thematic analysis in psychology. Qualitative research in psychology, 3(2), 77-101. https://doi.org/10.1191/1478088706qp063oa

Braun, V., Clarke, V., \& Weate, P. (2016). Using thematic analysis in sport and exercise 
research. In B. Smith \& A. Sparkes (Eds), Routledge Handbook of Qualitative Research in Sport and Exercise, 191-205. London, UK: Taylor and Francis Group.

Brooks, S. (2015). Does personal social media usage affect efficiency and wellbeing? Computers in Human Behavior, 46, 26-37. https://doi.org/10.1016 /j.chb.2014.12.053

Browning, B., \& Sanderson, J. (2012). The positives and negatives of Twitter: Exploring how student-athletes use Twitter and respond to critical tweets. International Journal of Sport Communication, 5(4), 503-521. https://doi.org/10.1123/ijsc.5.4.503

Creswell, J.W. (2014). Research design: Qualitative, quantitative, and mixed methods approaches (4th ed.) Thousand Oaks, CA: SAGE

Creswell, J. W., \& Miller, D. L. (2000). Determining validity in qualitative inquiry. Theory into practice, 39(3), 124-130.

Dale, G. A. (2000). Distractions and coping strategies of elite decathletes during their most memorable performances. The Sport Psychologist, 14(1), 17-41. https://doi.org $\underline{10.1123 / \mathrm{tsp} .14 .1 .17}$

David, J. L., Powless, M. D., Hyman, J. E., Purnell, D. M., Steinfeldt, J. A., \& Fisher, S. (2018). College Student Athletes and Social Media: The Psychological Impacts of Twitter Use. International Journal of Sport Communication, 11(2), 163-186. https://doi.org/10.1123/ijsc.2018-0044

Dohme, L. C., Bloom, G., Piggott, D., \& Backhouse, S. (2019). Development, Implementation, and Evaluation of an Athlete-Informed Mental Skills Training Program for Elite Youth Tennis Players. Journal of Applied Sport Psychology, 1-21. https://doi.org/10.1080/10413200.2019.1573204

Durand-Bush, N., \& Salmela, J. H. (2002). The development and maintenance of expert athletic performance: Perceptions of world and Olympic champions. Journal of 
Applied Sport Psychology, 14(3), 154-171. https://doi.org/10.1080 $\underline{10413200290103473}$

Encel, K., Mesagno, C., \& Brown, H. (2017). Facebook use and its relationship with sport anxiety. Journal of Sports Sciences, 35(8), 756-761. http://dx.doi.org/10.1080 $\underline{102640414.2016 .1186817}$

Etikan, I., Musa, S. A., \& Alkassim, R. S. (2016). Comparison of convenience sampling and purposive sampling. American Journal of Theoretical and Applied Statistics, 5(1), 14. https://doi.org/10.11648/j.ajtas.20160501.11

Farrington, N., Hall, L., Kilvington, D., Price, J., \& Saeed, A. (2014). Sport, Racism And Social Media. New York, NY: Routledge.

Filo, K., Lock, D., \& Karg, A. (2015). Sport and social media research: A review. Sport Management Review, 18(2), 166-181. https://doi.org/10.1016/j.smr.2014.11.001

Fitriana, M., \& Xin, T. Y. (2019). The athlete performance management: An impact of selfintegrity, family supports and social media. Journal of Education and Social Sciences, 12(2), 55-63. https://www.jesoc.com/wp-content/uploads/2019/04/KC12_044.pdf

Freeman, P., Rees, T., \& Hardy, L. (2009). An intervention to increase social support and improve performance. Journal of Applied Sport Psychology, 21(2), 186-200. https://doi.org/10.1080/10413200902785829

Frisby, C. M., \& Wanta, W. (2018). Media Hype and Its Influence on Athletic Performance. Advances in Journalism and Communication, 6(1), 1-18. https://doi.org/10.4236/ajc.2018.61001

Fynes-Clinton, J. (2012, August 02). The rise of social media among elite athletes has reached the stage where it is damaging performances says Jane Fynes-Clinton. The Courier Mail. Retrieved from https://goo.gl/x1nrSc

Galli, N., \& Vealey, R. S. (2008). “Bouncing back” from adversity: Athletes' experiences of 
resilience. The Sport Psychologist, 22(3), 316-335. https://doi.org/10.1123 $\underline{\text { tsp.22.3.316 }}$

Geurin, A. N. (2017). Elite Female Athletes' Perceptions of New Media Use Relating to Their Careers: A Qualitative Analysis. Journal of Sport Management, 31(4), 345-359. https://doi.org/10.1123/jsm.2016-0157

Geurin-Eagleman, A. N., \& Burch, L. M. (2016). Communicating via photographs: A gendered analysis of Olympic athletes' visual self-presentation on Instagram. Sport Management Review, 19(2), 133-145. https://doi.org/10.1016/j.smr.2015.03.002

Goodman, F. R., Kashdan, T. B., Mallard, T. T., \& Schumann, M. (2014). A brief mindfulness and yoga intervention with an entire NCAA Division I athletic team: An initial investigation. Psychology of Consciousness: Theory, Research, and Practice, 1(4), 339. http://dx.doi.org/10.1037/cns0000022

Gould, D., Greenleaf, C., Guinan, D., \& Chung, Y. (2002). A survey of US Olympic coaches: Variables perceived to have influenced athlete performances and coach effectiveness. The Sport Psychologist, 16(3), 229-250. https://doi.org/10.1123 $\underline{\text { tsp.16.3.229 }}$

Gratton, C., \& Jones, I. (2004). Research Methods for Sports Studies. London: Routledge.

Greenleaf, C., Gould, D., \& Dieffenbach, K. (2001). Factors influencing Olympic performance: interviews with Atlanta and Negano US Olympians. Journal of Applied Sport Psychology, 13(2), 154-184. https://doi.org/10.1080/104132001753149874

Guest, G., Bunce, A., \& Johnson, L. (2006). How many interviews are enough? An experiment with data saturation and variability. Field Methods, 18(1), 59-82. https://doi.org/10.1177/1525822X05279903

Gupta, A., Li, H., \& Sharda, R. (2013). Should I send this message? Understanding the impact of interruptions, social hierarchy and perceived task complexity on user 
performance and perceived workload. Decision Support Systems, 55(1), 135-145. https://doi.org/10.1016/j.dss.2012.12.035

Hambrick, M. E., \& Mahoney, T. Q. (2011). 'It's incredible-trust me': exploring the role of celebrity athletes as marketers in online social networks. International Journal of Sport Management and Marketing, 10(3-4), 161-179. https://doi.org/10.1504 /IJSMM.2011.044794

Hayes, M., Filo, K., Riot, C., \& Geurin, A. (2019). Athlete Perceptions of Social Media Benefits and Challenges During Major Sport Events. International Journal of Sport Communication. Advanced online publication, 1-33.

Heinonen, K. (2011). Consumer activity in social media: Managerial approaches to consumers' social media behavior. Journal of Consumer Behaviour, 10(6), 356-364. https://doi.org/10.1002/cb.376

Hodge, C., \& Walker, M. (2015). Personal branding: a perspective from the professional athlete-level-of-analysis. International Journal of Sport Management and Marketing, 16(1-2), 112-131. https://doi.org/10.1504/IJSMM.2015.074920

Hogan, K., \& Norton, K. (2000). The 'price' of Olympic gold. Journal of science and medicine in sport, 3(2), 203-218. https://doi.org/10.1016/S1440-2440(00)80082-1

Horton, J., Macve, R., \& Struyven, G. (2004). Qualitative research: experiences in using semistructured interviews. The Real Life Guide to Accounting Research, 339-357.

Jensen, M., George, M. J., Russell, M. R., \& Odgers, C. L. (2019). Young Adolescents' Digital Technology Use and Mental Health Symptoms: Little Evidence of Longitudinal or Daily Linkages. Clinical Psychological Science. Advanced online publication. https://doi.org/10.1177/2167702619859336

Johnson, B. K., \& Knobloch-Westerwick, S. (2014). Glancing up or down: Mood management and selective social comparisons on social networking sites. Computers 
in Human Behavior, 41, 33-39. https://doi.org/10.1016/j.chb.2014.09.009

Karageorghis, C., \& Terry, P. (2011). Inside Sport Psychology. Champaign, IL: Human Kinetics.

Kavanagh, E., Jones, I., \& Sheppard-Marks, L. (2016). Towards typologies of virtual maltreatment: sport, digital cultures \& dark leisure. Leisure Studies, 35(6), 783-796. https://doi.org/10.1080/02614367.2016.1216581

Kristiansen, E., Hanstad, D. V., \& Roberts, G. C. (2011). Coping with the media at the Vancouver Winter Olympics:"We all make a living out of this”. Journal of Applied Sport Psychology, 23(4), 443-458. https://doi.org/10.1080/10413200.2011.598139

Lincoln, Y. S., \& Guba, E. G. (1985). Naturalistic inquiry. Newbury Park, CA: Sage.

Litchfield, C., Kavanagh, E. J., Osborne, J., \& Jones, I. (2016). Virtual Maltreatment: Sexualisation and Social Media Abuse in Sport. Psychology of Women Section Review, 18(2).

Litchfield, C., Kavanagh, E., Osborne, J., \& Jones, I. (2018). Social media and the politics of gender, race and identity: the case of Serena Williams. European Journal for Sport and Society, 15(2), 154-170. https://doi.org/10.1080/16138171.2018.1452870

Morrow, S. L. (2005). Quality and trustworthiness in qualitative research in counseling psychology. Journal of Counseling Psychology, 52(2), 250. https://doi.org/10.1037 $\underline{10022-0167.52 .2 .250}$

Noblet, A. J., \& Gifford, S. M. (2002). The sources of stress experienced by professional Australian footballers. Journal of Applied Sport Psychology, 14(1), 1-13. https://doi.org/10.1080/10413200209339007

Ottesen, D. (2012, July 31). London 2012 Olympics: Australian swimmer Emily Seebohm blames Twitter and Facebook for failure. The Telegraph. Retrieved from https://goo.gl/zgkKj2 
1 Oudejans, R. R., Kuijpers, W., Kooijman, C. C., \& Bakker, F. C. (2011). Thoughts and attention of athletes under pressure: skill-focus or performance worries? Anxiety, Stress, \& Coping, 24(1), 59-73. https://doi.org/10.1080/10615806.2010.481331

Park, S., \& Lavallee, D. (2015). Roles and influences of Olympic athletes' entourages in athletes' preparation for career transition out of sport. Sport and Exercise Psychology Review, 11(1), 3-19.

Parmentier, M. A., \& Fischer, E. (2012). How athletes build their brands.International Journal of Sport Management and Marketing, 11(1-2), 106-124. https://doi.org $\underline{\text { 10.1504/IJSMM.2012.045491 }}$

Petersen, T. (1993). Recent advances in longitudinal methodology. Annual Review of Sociology, 19(1), 425-454. https://doi.org/10.1146/annurev.so.19.080193.002233

Rees, T., \& Hardy, L. (2000). An investigation of the social support experiences of high-level sport performers. The Sport Psychologist, 14(4), 327-347. https://doi.org/10.1123 tsp.14.4.327

Richards, D., Caldwell, P. H., \& Go, H. (2015). Impact of social media on the health of children and young people. Journal of Paediatrics and Child Health, 51(12), 11521157. https://doi.org/10.1111/jpc. 13023

Sanders, G. S., Baron, R. S., \& Moore, D. L. (1978). Distraction and social comparison as mediators of social facilitation effects. Journal of Experimental Social Psychology, 14(3), 291-303. https://doi.org/10.1016/0022-1031(78)90017-3

Sanderson, J., Browning, B., \& Schmittel, A. (2015). Education on the digital terrain: A case study exploring college athletes' perceptions of social-media training. International Journal of Sport Communication, 8(1), 103-124. https://doi.org/10.1123/IJSC.2014$\underline{0063}$

Sanderson, J., \& Truax, C. (2014). “I hate you man!": Exploring maladaptive parasocial 
interaction expressions to college athletes via Twitter. Journal of Issues in Intercollegiate Athletics, 7, 333-351.

Smith, M. J., Arnold, R., \& Thelwell, R. C. (2018). “There's No Place to Hide”: Exploring the Stressors Encountered by Elite Cricket Captains. Journal of Applied Sport Psychology, 30(2), 150-170. https://doi.org/10.1080/10413200.2017.1349845

Smith, B., \& McGannon, K. R. (2018). Developing rigor in qualitative research: Problems and opportunities within sport and exercise psychology. International Review of Sport and Exercise Psychology, 11(1), 101-121. https://doi.org/10.1080 $\underline{1750984 X .2017 .1317357}$

Sparkes, A. (Ed.). (1992). Research in physical education and sport: Exploring alternative visions (pp 9-60). Psychology Press. London: Taylor and Francis.

Stewart, B., Nicholson, M., Smith, A., \& Westerbeek, H. (2005). Australian Sport - Better by Design? London, UK: Routledge.

Suri, H. (2011). Purposeful sampling in qualitative research synthesis. Qualitative research journal, 11(2), 63-75. https://doi.org/10.3316/QRJ1102063

Thelwell, R.C., Weston, N.J.V., \& Greenless, I.A. (2007). Batting on a sticky wicket: Identifying sources of stress and associated coping strategies for professional cricket batsmen. Psychology of Sport and Exercise, 8, 219-232. https://doi.org/10.1016 /i.psychsport.2006.04.002

Tracy, S. J. (2013). Qualitative research methods. UK: Wiley-Blackwell.

Turner, M. J., \& Barker, J. B. (2013). Resilience: lessons from the 2012 Olympic Games. Reflective Practice, 14(5), 622-631. https://doi.org/10.1080 $\underline{14623943.2013 .835724}$

Twenge, J. M., Joiner, T. E., Rogers, M. L., \& Martin, G. N. (2018). Increases in depressive symptoms, suicide-related outcomes, and suicide rates among US adolescents after 

2010 and links to increased new media screen time. Clinical Psychological Science, 6(1), 3-17. https://doi.org/10.1177/2167702617723376

Ungerleider, S. (2005). Mental training for peak performance: Top athletes reveal the mind exercises they use to excel. USA: Rodale Inc.

5 Vakhitova, Z. I., \& Bell, P. J. (2018). A script analysis of the role of athletes' support networks as social facilitators in doping in sport. Crime Prevention and Community Safety, 20(3), 168-188. https://doi.org/10.1057/s41300-018-0045-8

Vogel, E. A., Rose, J. P., Roberts, L. R., \& Eckles, K. (2014). Social comparison, social media, and self-esteem. Psychology of Popular Media Culture, 3(4), 206. http://dx.doi.org/10.1037/ppm0000047

11 Wimmer, R. D., \& Dominick, J. R. (2003). Mass media research: An introduction. Belmont, CA: Wadsworth. 


\section{Tables and Figures}

Table 1

Interviewee Demographics $(N=15)$

\begin{tabular}{cllll}
\hline Interview & Pseudonym & Age & Gender & Sport \\
\hline 1 & Gwen & 34 & Female & Climbing \\
2 & Lincoln & 27 & Male & Sailing \\
3 & Yvonne & 18 & Female & Open Water Swimming \\
4 & Sam & 19 & Male & Badminton \\
5 & Victoria & 31 & Female & Water Polo \\
6 & Vincent & 27 & Male & Ski Cross \\
7 & Evelyn & 25 & Female & Snowboard Cross \\
8 & Chloe & 20 & Female & Mogul Skiing \\
9 & Natalie & 24 & Female & Freestyle/Mogul Skiing \\
10 & Matilda & 30 & Female & Lawn Bowls \\
11 & Robert & 27 & Male & Basketball \\
12 & Warren & 33 & Male & Aerial Skiing \\
13 & Oscar & 20 & Male & Mountain Bike \\
14 & Gabriella & 26 & Female & Soccer \\
15 & Vanessa & 21 & Female & Athletics \\
\hline
\end{tabular}


Table 2

Themes, Operational Definitions, and Example Quotes

\begin{tabular}{|c|c|c|}
\hline Theme & Operational Definition & Example Quote \\
\hline Obligation to Respond & $\begin{array}{l}\text { Athletes receiving an influx of } \\
\text { messages and feeling compelled to } \\
\text { reply. }\end{array}$ & $\begin{array}{l}\text { "It's just like sometimes you don't have the time to reply back, and } \\
\text { you're like, oh maybe I should, maybe I shouldn't sort of thing. I } \\
\text { definitely haven't replied to all my messages since I got them, I just } \\
\text { don't have time to read through all of them and do all these individual } \\
\text { messages back, lots of stuff. But it is nice. Like, it is encouraging." }\end{array}$ \\
\hline $\begin{array}{l}\text { Susceptibility to Unwanted } \\
\text { Commentary }\end{array}$ & $\begin{array}{l}\text { Social media providing an avenue for } \\
\text { followers to direct antagonistic } \\
\text { messages to athletes. }\end{array}$ & $\begin{array}{l}\text { "Normally it doesn't bother me, and I'm quite entertained by people } \\
\text { trying to troll me, because I find it pretty funny, but it's not stuff that } \\
\text { you want to read when you're extra stressed. Just to put a doubt in } \\
\text { your mind... Some people get really upset by it." }\end{array}$ \\
\hline $\begin{array}{l}\text { Pressure to Build and } \\
\text { Maintain an Athlete Brand }\end{array}$ & $\begin{array}{l}\text { The perception that creating a brand on } \\
\text { and through social media is time } \\
\text { consuming and can distract athletes } \\
\text { from focusing on the event. }\end{array}$ & $\begin{array}{l}\text { "When they compete, they're sort of like, torn between what I should } \\
\text { do and what I should look like, and stuff, and between actually just } \\
\text { competing and let their results sort of show." }\end{array}$ \\
\hline Competitor Content & $\begin{array}{l}\text { Some athletes who see their } \\
\text { competitors' posts on social media may } \\
\text { rethink their preparation leading up to } \\
\text { the event. }\end{array}$ & $\begin{array}{l}\text { "You can appreciate what they're doing, but not worry about it. And } \\
\text { that comes with practise and experience, and a bit of maturity and } \\
\text { stuff, but for sure, for some of the younger people, it absolutely gets to } \\
\text { them. And I know that, so that's why I put some stuff up." }\end{array}$ \\
\hline Mood Management & $\begin{array}{l}\text { Athletes seeking a distraction or } \\
\text { reprieve from the sport/competition } \\
\text { through social media during an event. }\end{array}$ & $\begin{array}{l}\text { "It gives me some time to switch off and not think about it and get } \\
\text { distracted. Sometimes distraction is actually a really good thing." }\end{array}$ \\
\hline
\end{tabular}


Need for Self-Awareness Athletes being aware of how social media effects them, discovering what works for them to minimise any impacts, and prioritising activities.

Switching Off and Handing Over Control
Athletes switching off from their social media for a specified period of time (i.e., during competition) or handing their accounts over to someone else to manage throughout an event.
"You've got to, you know set your priorities and go on it when you should be on it, and not on it when you shouldn't be on it."

"So, I found personally for me, I found it quite beneficial; what I did I deleted the apps off my phone and I had my sister running um, my social media accounts during the events." 


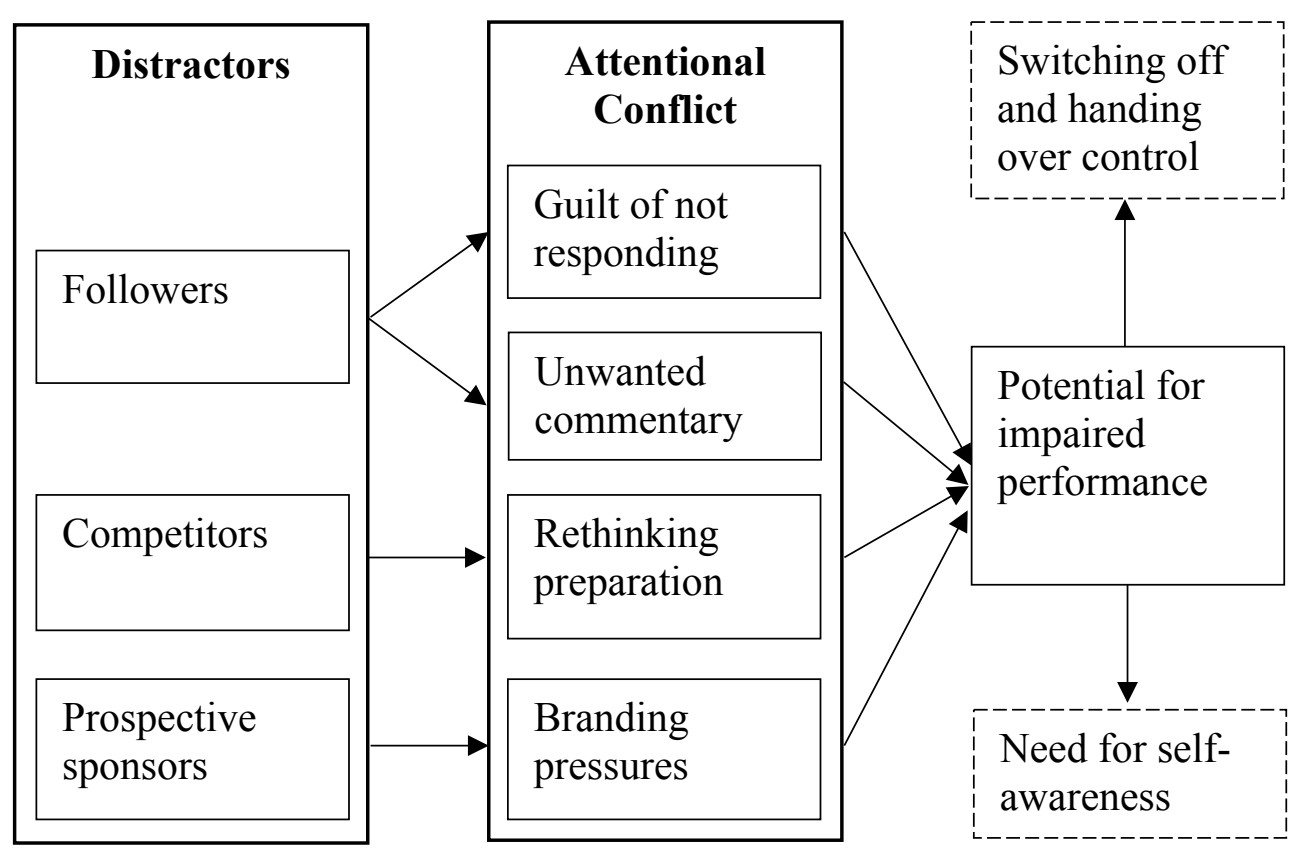

Figure 1. Conceptual DCT model 


\section{Appendix A: Interview Guide}

\begin{tabular}{|c|c|}
\hline Age: & Gender: \\
\hline Event: & Sport: \\
\hline \multicolumn{2}{|c|}{ Number of representative years: } \\
\hline $\begin{array}{c}\text { Topic } 1 \\
\text { Introduction } \\
\& \\
\text { DCT Theory }\end{array}$ & $\begin{array}{l}\text { 1. Do you think using social media is distracting during the preparation } \\
\text { phase of a major sport event? Please elaborate on why you think this. } \\
\text { 2. Do you think using social media is distracting during the major sport } \\
\text { event? Please elaborate on why or why not you think this. } \\
\text { 3. Did you have a plan for using social media during <insert event }>\text { ? } \\
\text { 4. Did you feel pressured to post or be on social media during the event? } \\
\text { Please elaborate. } \\
\text { a. If so, who provided this pressure? } \\
\text { 5. When accessing your social media accounts, did you read messages } \\
\text { and posts that followers sent you via social media during <insert } \\
\text { event }>\text { ? } \\
\text { a. If yes, how did you react to or treat positive messages or } \\
\text { messages of support? } \\
\text { b. If yes, how did you react to or treat unwanted and negative } \\
\text { messages? } \\
\text { c. If no, why did you choose not to read any messages? } \\
\text { 6. How do you perceive these messages in terms of distraction during a } \\
\text { major event? Do you find them distracting or part of everyday life? } \\
\text { 7. Do you read every comment or reply made on a post of yours? } \\
\text { 8. How do you perceive the pressure to perform through social media } \\
\text { when compared with traditional media? }\end{array}$ \\
\hline $\begin{array}{c}\text { Topic 2A } \\
\text { DCT Theory } \\
\text { social media } \\
\text { as a negative } \\
\text { distraction }\end{array}$ & $\begin{array}{l}\text { 9. Did you ever feel a little separation anxiety from your phone or social } \\
\text { media while you were warming up or getting ready to compete? } \\
\text { 10. Was there a time when or where your attention was focused on social } \\
\text { media rather than the event you were competing in? Please describe } \\
\text { this experience. } \\
\text { a. How did this time potentially impact your performance? } \\
\text { 11. How could a reliance or time spent on social media affect athletic } \\
\text { performance levels? Please elaborate on your thoughts. } \\
\text { 12. How do you think you could minimise social media distractions for } \\
\text { future events? Would you consider doing this? }\end{array}$ \\
\hline $\begin{array}{c}\text { Topic 2B } \\
\text { DCT Theory } \\
\text { social media } \\
\text { as a positive } \\
\text { distraction }\end{array}$ & $\begin{array}{l}\text { 13. How did you manage your social media use during the event so it did } \\
\text { not cause a distraction to you? Please elaborate on your strategies. } \\
\text { 14. Do you use social media as a positive/or escape? (e.g., read content } \\
\text { unrelated to your sport/event). If so, how? } \\
\text { 15. Do you think using social media as a positive resource can benefit } \\
\text { your performance? If so, how and please elaborate on why you think } \\
\text { this. } \\
\text { 16. Why do you think social media is distracting for some athletes and } \\
\text { not others? }\end{array}$ \\
\hline
\end{tabular}

